Bio-grafía. Escritos sobre la Biología y su Enseñanza. ISSN 2027-1034

Número Extraordinario. p.p. 182-191

Memorias del Primer encuentro ambiental Universidad, ambiente y sustentabilidad: experiencias y prácticas.

\title{
COLOMBIA SIN ASBESTO (Perspectiva ambiental)
}

\author{
Corredor Castañeda Camila Andrea ${ }^{1}$ \\ Gutiérrez Garzón Cesar Augusto ${ }^{1}$ \\ Zea Zambrano Ángela ${ }^{1}$
}

\section{Resumen}

El asbesto también conocido como amianto crisotilo, es un conjunto de seis minerales de silicato de origen natural, los cuales, tiene un hábito asbestiforme, es decir, contiene fibras largas y resistentes que se pueden separar y son suficientemente flexibles. Por contar con gran versatilidad, este material es utilizado en la industria como materia prima para la elaboración de diversos artículos que se emplean en la cotidianidad. Sin embargo, dada su estructura y propiedades físico-químicas evidencia alto riesgo para la salud de las personas que han tenido contacto directo o indirecto con él. (Montesa, 2005)

Ésta situación se produce, porque las fibras de asbesto pueden ser transportadas por vía aérea o acuosa a causa de la degradación de depósitos naturales o de productos manufacturados. Y como éste es un mineral que no puede ser degradado por el agua, ni por ácidos y mucho menos por altas temperaturas; las partículas que cuentan con diámetros demasiado pequeños pueden mantenerse suspendidas en el aire por largo tiempo. (EUA D. d., 2002). Es por ello que tienen la posibilidad de recorrer largas distancias y ser inhaladas causando problemas de salud en individuos que no se encuentran relacionados directamente con el sitio de producción y/o explotación del mineral.

A pesar de lo descrito y aun cuando más de 55 países prohíben su uso, en Colombia, no contamos con reglamentación jurídica, que regule en términos ambientales a la industria asociada a la explotación y uso del amianto. De tal suerte que la ciudadanía se encuentra desprotegida frente a esta fibra mortal mientras se da prelación a las empresas y a sus intereses económicos. Por ello los primeros afectados terminan siendo los trabajadores de éste sector industrial, sus familias y la población circundante a los espacios de explotación de asbesto o a empresas que

${ }^{1}$ Universidad Pedagógica Nacional, Estudiante de Licenciatura en Química, SISMA Semillero de investigación en salud y medio ambiente. Email: camiandrea89@gmail.com 
Bio-grafía. Escritos sobre la Biología y su Enseñanza. ISSN 2027-1034

Número Extraordinario. p.p. 182-191

Memorias del Primer encuentro ambiental Universidad, ambiente y sustentabilidad: experiencias y prácticas.

trabajan con este mineral como materia prima, dadas a las condiciones ambientales, geográficas y políticas a las cuales han estado expuestas. (Cárcoba, 2014)

\section{Palabras claves}

Asbesto, Cáncer, Mesotelioma, Ambiente, Material Partículas.

\section{Abstract}

The asbestos also known as "chrysotile or amianto", it's a material that contains long fibres and strong that you can detach them and are enough felixible, its uses in differents insdustries as raw material to produce different articles that are in use in the commonness. This material has a great versatility and have been archived to show a high health risk for direct contact or indirect contact with him.

This situation is produced, because the asbesto" s fiber could be transported by air or water to cause of the degradation of natural deposits or manufacturated products. And as this is a mineral that cannot be degradated by water, acids or high temperatures; For this reason they have too small diameters can be kept suspended in the air in long time. It is for it that they have the possibility of crossing long distances and be inhaled causing problems of health in people who aren"t related directly to the site of production and / or exploitation of the mineral.

In spite of the described thing and in spite of that more than 55 countries prohíbited his use, in Colombia, we dont have with juridical regulation, that to regulate in environmental terms to the industry associated with the exploitation and use of the amianto. In such a way that the citizenship is unprotected opposite to this mortal fiber while one gives marshaling to the companies and to his (her, your) economic interests. For it the first affected ones end up by being the workers of this one industrial sector, his(her, your) families and the surrounding population to the spaces of exploitation (development) of asbestos or to companies that work with these mineral as raw material, started to the environmental, geographical and political conditions to which they have been exposed.

\section{Keywords}

Asbestos, Cancer, Environment, Particulate matter, Mesothelioma 
Bio-grafía. Escritos sobre la Biología y su Enseñanza. ISSN 2027-1034

Número Extraordinario. p.p. 182-191

Memorias del Primer encuentro ambiental Universidad, ambiente y sustentabilidad: experiencias y prácticas.

\section{OBJETIVOS}

- Realizar una exploración acerca de la relación de conceptos químicos asociados a patologías producidas por el contacto con asbesto.

- Indagar las características ambientales del pueblo de Sibaté que pueden estar favoreciendo la incidencia de patologías asociadas con el uso de asbesto.

- Elaborar un material de divulgación que permita orientar a los habitantes sobre los riesgos en la salud asociados al uso de asbesto.

\section{MARCO TEÓRICO}

Asbesto o Amianto es el nombre designado a un mineral de origen natural utilizado en distintos sectores industriales. Es un material fibroso, resistente y de gran versatilidad, por lo que cuenta con diversas aplicaciones industriales. Estas fibras de amianto son duraderas, resistentes al calor y bastante económicas. Por estas razones, han sido utilizadas ampliamente en la elaboración de productos industriales, principalmente en la construcción. (Cárcoba, 2014)

\section{Tipos de asbesto}

Existen dos tipos de asbesto, crisotilo y anfibolita. El crisotilo tiene fibras largas y flexibles y es el más utilizado en la industria mientras que las fibras de anfibolita, poseen forma de barras y no se utilizan frecuentemente en los productos comerciales. Sin embargo, se puede afirmar que la exposición a estos tipos de asbesto hace que aumente la probabilidad de contraer enfermedades relacionadas con el mineral. Se piensa que en comparación con el asbesto crisotilo, las fibras de anfibolita aumentan las probabilidades de contraer enfermedades, puesto que se encuentran en mayor proporción en las biopsias realizadas a pacientes que padecen de enfermedades tales como el mesotelioma. Razón por la cual, se ha establecido un límite de exposición a dicho material. (Cárcoba, 2014) 
Bio-grafía. Escritos sobre la Biología y su Enseñanza. ISSN 2027-1034

Número Extraordinario. p.p. 182-191

Memorias del Primer encuentro ambiental Universidad, ambiente y sustentabilidad: experiencias y prácticas.

\section{Medio Ambiente.}

Cuando las personas inhalan aire se sabe que éste contiene partículas microscópicas; estas partículas son filtradas por los pulmones ya que por sus propiedades son estériles. Órganos como la nariz y los bronquios que son las vías aéreas que conducen a los pulmones normalmente podrían bloquear a los anfíboles.

Las partículas de asbesto (llamadas anfíboles) son largas, delgadas y ligeras, las fibras microscópicas como éste no son filtradas por la nariz o los bronquios, como ha sido mencionado anteriormente sus propiedades físicas les permiten evadir los obstáculos filtros y controles de los órganos mencionados, haciendo más sencilla su entrada a los pulmones, creando la afección que se verá reflejada a lo largo de los años.

Límite ambiental, control de exposición al polvo de asbesto y controles de ingeniería

Solo se podrá tener una exposición de $0.1 \mathrm{fibras} / \mathrm{cm}^{3}$ para un periodo de ocho horas, límite establecido para todas las variedades de asbesto o amianto.

Se debe evitar el contacto con éste polvo y en caso que sea necesario, el control debe realizarse lo más cerca a la fuente o la fábrica para impedir su dispersión y mitigar el riesgo ambiental.

Adicionalmente en los lugares que se trabaje con éste tipo de material, se debe realizar "Un buen control de ingeniería que debe incluir los siguientes equipos:

- Campanas de polvo;

- Conductos;

- Colector de polvo y ventiladores;

- Aire adicional".

(Boletin del Instituto del Crisotilo 2010)

Peligros de exposición al asbesto para los trabajadores.

Cuando las fibras de asbesto son inhaladas por los trabajadores puede presentarse una incidencia de enfermedades pulmonares y afectaciones en los órganos donde éstas se depositan. (Morales, 2013) 
Bio-grafía. Escritos sobre la Biología y su Enseñanza. ISSN 2027-1034

Número Extraordinario. p.p. 182-191

Memorias del Primer encuentro ambiental Universidad, ambiente y sustentabilidad: experiencias y prácticas.

La patogénesis se desarrolla mediante diferentes fases. Inicialmente el material es inhalado, éste se aloja directamente en la capa pleural y los alvéolos pulmonares activando los mecanismos de protección del sistema inmune y generando la consabida inflamación, posteriormente se entra en un periodo silente, durante el cual se desarrolla la patología sin presentarse mayores síntomas o situaciones de alarma.

\section{$4 t^{2}=$}

- 1 a.

Subsecuentemente y después de un periodo mayor a 20 años se empiezan a evidenciar diversas señales que pueden ser asociadas a otras enfermedades, propias del sistema respiratorio; es así como en la mayoría de los casos se da un tratamiento enfocado a las enfermedades predichas sin llegar a feliz término, por esta razón, los pacientes afectados acuden una vez más al concepto médico y después de pruebas más específicas se comprueba que se trata de un tipo de cáncer llamado mesotelioma pleural. (Morales, 2013)

\section{¿Quién corre riesgo de estar expuesto al asbesto?}

Las personas que se van a estar mayormente afectadas:

- Minas de explotación de asbesto.

- Fábricas cuya materia prima sea este mineral.

- Edificios, casas, construcciones, etc, que se encuentren en proceso de demolición y posean dentro de su estructura piezas que contengan asbesto.

- Espacios de desechos de asbesto donde no exista un manejo adecuado; es decir, lugares en donde el material se encuentre al aire libre en donde se facilite el transporte de las partículas más pequeñas de este material.

Por otra parte, se tiene que considerar que en interiores, la concentración de asbesto puede aumentarse en las siguientes condiciones:

- Si el producto manufacturado con amianto es utilizado como material de construcción para la casa y si estos no están en buenas condiciones o deteriorados y se desmoronan fácilmente.

- En caso de una restauración de la casa o demolición de objetos que contengan asbesto. 
Bio-grafía. Escritos sobre la Biología y su Enseñanza. ISSN 2027-1034

Número Extraordinario. p.p. 182-191

Memorias del Primer encuentro ambiental Universidad, ambiente y sustentabilidad: experiencias y prácticas.

- El asbesto ha sido transportado por medio de la ropa, los zapatos u otra parte del cuerpo (esto para casos en los que los trabajadores regresan a casa con ropa, uniformes o artículos que fueron utilizados en lugares donde tuvieron contacto directo con el mineral). (Atsdr.C., 2016)

\section{Requisitos de registros para las exposiciones de asbesto.}

Se mantendrá un registro preciso sobre:

- Monitoreo médico de los trabajadores que están directamente en contacto con la exposición de asbesto, todos los informes médicos, incluyendo opiniones escritas y demás, se harán por el tiempo que el operario realice su labor y durante 30 años adicionales.

- Los registros de entrenamiento, por un año después de la última fecha de empleo. (EUA D. d., 2002)

\section{¿Dónde se ha utilizado el asbesto o amianto?}

El amianto o asbesto lo podemos encontrar en productos tales como:

- Productos de laboratorio.

- Material de construcción. En la elaboración de cementos, tejas, tanques de agua, tuberías, cubiertas, etc.

- Algunos textiles.

- Piezas mecánicas.

- En la parte naval, entre otros.

- Paneles aislantes térmicos y de ruido.

- Conductos de aire.

- En distintos aerosoles. 
Bio-grafía. Escritos sobre la Biología y su Enseñanza. ISSN 2027-1034

Número Extraordinario. p.p. 182-191

Memorias del Primer encuentro ambiental Universidad, ambiente y sustentabilidad: experiencias y prácticas.

\section{METODOLOGÍA}

El trabajo se realizó en tres fases:

- La primera correspondió al desarrollo teórico, es decir, a una fase exploratoria en la que se relacionaron conceptos químicos aplicados a las patologías producidas por asbesto.

- Durante la segunda fase se realizó un abordaje específico, en el que se pretendía tener un reconocimiento del pueblo de Sibaté (por ser el lugar geográfico cercano, más afectado por la contaminación con amianto) y evidenciar las características ambientales que allí se presentan para relacionarlas con su incidencia frente al desarrollo de patologías. Mientras que, en paralelo, se podía reconocer la posición de sus habitantes respecto a la contaminación con el material de nuestro interés. Durante ésta fase y teniendo en cuenta el contexto, se realizaron una serie de entrevistas a una muestra representativa de la población.

- Durante la tercera fase se dio paso a la creación de un material de divulgación sobre los peligros ambientales provenientes del asbesto, así mismo se realizó un video en el que se materializa todo lo recogido en las entrevistas.

- Tanto el material de divulgación como el video realizado, fueron socializados en el primer foro estudiantil Colombia libre de asbesto, desarrollado en el primer semestre de 2016 en la Universidad Pedagógica Nacional y durante el primer encuentro ambiental de la Facultad de Ciencia y Tecnología.

Así mismo, se dio inicio a una relación académica con Universidad Pedagógica y Tecnológica de Colombia (UPTC), específicamente con el Grupo de Investigación Biomédica y de Patología (GIBP) mediante la cual se proyectó el segundo foro estudiantil "Colombia Sin Asbesto" a desarrollarse en la ciudad de Tunja y la concreción de un proyecto conjunto que nos permita seguir trabajando en este tema. Tanto a nivel del área de salud, como en la concreción de piezas comunicativas que logren tener suficiente asertividad para divulgar los riesgos de esta fibra y los mecanismos de protección ambiental que pueden desarrollarse en la nación. 
Bio-grafía. Escritos sobre la Biología y su Enseñanza. ISSN 2027-1034

Número Extraordinario. p.p. 182-191

Memorias del Primer encuentro ambiental Universidad, ambiente y sustentabilidad: experiencias y prácticas.

\section{RESULTADOS}

- En el barrio Pablo Neruda del pueblo de Sibaté, se evidenció que la muestra representativa de la población tiene conocimiento frente a que el sitio de construcción de sus casas está sobre residuos de Eternit que, en épocas anteriores fueron depositados allí sin ningún tipo de aviso. Sin embargo, esto no genera ningún tipo de reacción, dado que sus habitantes, no manifiestan algún conocimiento sobre cómo tratar los residuos de dicha fábrica, tanto así que los nuevos residuos que allí se depositan son usados frecuentemente como material de construcción y/o adorno para sus casas sin ninguna precaución aparente.

- Los habitantes de este barrio no tienen el convencimiento de que la fibra de Asbesto puede ocasionarles algún tipo de cáncer en sus pulmones. Como historia cotidiana, los pobladores se cuentan los casos que han ocurrido en sus familias con personas que han tenido exposición directa con dicha fibra pero aun así se mantienen escépticos y/o no ven la relación entre los sucesos y la presencia del amianto.

- De las entrevistas realizadas pudimos observar que aun con todo lo que se ha dicho sobre este mineral y los casos presentados por asbestosis $y / 0$ mesotelioma en Sibaté y sus cercanías. El factor socio económico incide en las decisiones que toman los pobladores puestos que al no contar con recursos suficientes y tener la necesidad de residencia y posibilidad laboral, los habitantes del sector terminan por aceptar las condiciones que Eternit les brinda.

Figura1: Residuos de materiales que contiene asbesto en el pueblo de Sibaté, Mayo 2016 
Bio-grafía. Escritos sobre la Biología y su Enseñanza. ISSN 2027-1034

Número Extraordinario. p.p. 182-191

Memorias del Primer encuentro ambiental Universidad, ambiente y sustentabilidad: experiencias y prácticas.

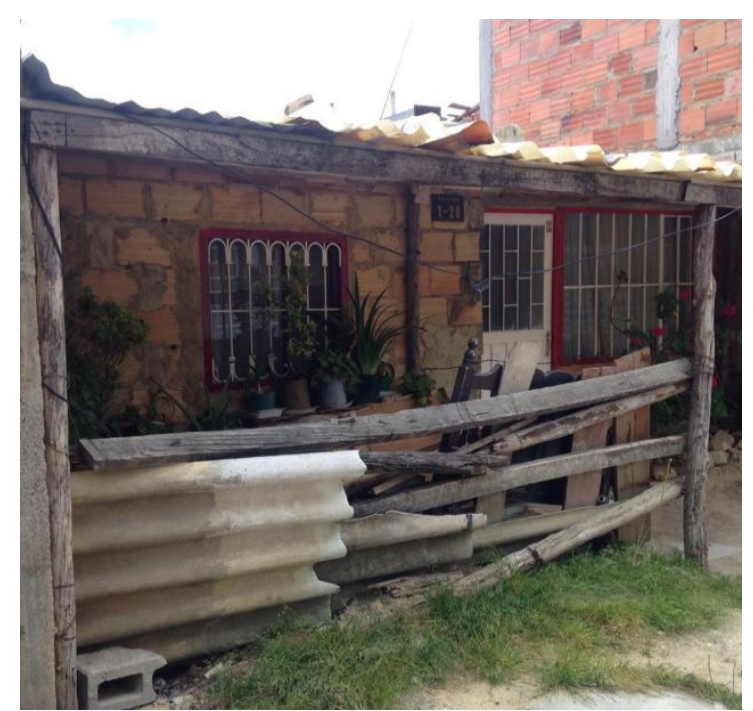

Figura 2: En distintas casas del pueblo de Sibaté se utilizan distintos materiales que contienen asbesto, mayo 2016.

\section{CONCLUSIONES}

- Por medio de la exploración de conceptos químicos asociados a las patologías producidas por el contacto con asbesto, se elaboró un material de divulgación que permitió orientar a los habitantes sobre los riesgos en la salud asociados al uso de asbesto. De esta forma, se inició una relación académica, la cual tiene como fin dar un conocimiento y reflexión para una Colombia sin Asbesto, la cual se tiene previsto desarrollarse en Tunja.

Siendo así, se infiere que el presente proyecto, permitió distinguir las problemáticas que trae este asbesto y a su vez da paso para desarrollo de trabajos que relacionen este tema tanto a nivel del área de salud, como en la concreción de piezas comunicativas que logren tener suficiente asertividad para divulgar los riesgos de esta fibra y los mecanismos de protección ambiental que pueden desarrollarse en la nación

- El asbesto es el enemigo silencioso que nuestro país no quiere aceptar, ¿es el factor económico la razón por la que no se emite una prohibición? Aun cuando se sabe que ello podría salvar miles de vidas.

- En el barrio Pablo Neruda del pueblo de Sibaté se presenta gran incidencia de patologías relacionadas con la fibra de asbesto; sin embargo muchos de sus habitantes no cuentan con información básica sobre la fibra, no saben que en épocas anteriores fueron depositados residuos de asbesto por el sector y que la volatilidad de esta fibra, aunada con las condiciones 
Bio-grafía. Escritos sobre la Biología y su Enseñanza. ISSN 2027-1034

Número Extraordinario. p.p. 182-191

Memorias del Primer encuentro ambiental Universidad, ambiente y sustentabilidad: experiencias y prácticas.

geográficas y ambientales, los deja en un grado de riesgo y vulnerabilidad inmenso. Por ello, muchas de las casas construidas allí, por no decir todas, tienen relación directa con la fibra mortal, por estar ubicadas sobre residuos de asbesto, por tener piezas de éste material en su estructurado porque algunos de los residuos, y actualmente no se cuenta con un manejo ambiental apropiado para el sector. ¿Seguiremos en silencio?

\section{A) $t$ th \\ BIBLIOGRAFÍA}

- Finalmente, Colombia presenta un alto grado de contaminación por asbesto en pueblos tales como Sibaté barrió Pablo Neruda que es principalmente afectado por la empresa Eternit y Campamento Antioquia afectado por la mina de explotación de asbesto Las Brisas.

Atsdr.C. (2016). .Division of Toxicology and Human Health Sciences. Retrieved 10 30, 2016, from www.atsdr.cdc.gov

Cárcoba Alonso, Á., Rodríguez Panadero, F., García Jiménez, J., Santos Sánchez, V. d., \& Gallardo García, V. (2014). Amianto: Impacto sobre la Salud y el Medio Ambiente. Retrieved 31 de 10 de 2016, from tu salud no esta en nomina: www.tusaludnoestaennomina.com

EUA, D. d. (2002). Peligro Asbesto osha hoja informativa.Retrieved 1031 , 2016, from Nevada Department of Business and Industry: http://4safenv.state.nv.us/

Giticsa. (s.f.) (n.d.). giticsa. Retrieved 10 28, 2016, from servicios tecnicos industriales: http://www.giticsa.com/

Boletin del Instituto del Crisotilo (2010). Para el Uso Seguro y Responsable del Crisotilo. (2010). V. 9 N. 2. Recuperado el 31 de octubre de 2016 de http://www.chrysotile.com/data/Bulletin_V9_No2-Esp.pdf

Montesa, I. A. (2005). Normativa sobre el asbesto y sus enfermedades pleuropulmonares. Arch Bronconeumol , 41:153-68. 